\title{
Classical molecular dynamics and quantum abs-initio studies on lithium-intercalation in interconnected hollow spherical nano-spheres of amorphous Silicon
}

Bhowmik, Arghya; Malik, R.; Prakash, S.; Sarkar, Tanmay ; Bharadwaj, Mridula Dixit ; Aich, S.; Ghosh, Sourov

Published in:

Journal of Alloys and Compounds

Link to article, DOI:

10.1016/j.jallcom.2015.10.274

Publication date:

2016

Document Version

Peer reviewed version

Link back to DTU Orbit

Citation $(A P A)$ :

Bhowmik, A., Malik, R., Prakash, S., Sarkar, T., Bharadwaj, M. D., Aich, S., \& Ghosh, S. (2016). Classical molecular dynamics and quantum abs-initio studies on lithium-intercalation in interconnected hollow spherical nano-spheres of amorphous Silicon. Journal of Alloys and Compounds, 665, 165-172.

https://doi.org/10.1016/j.jallcom.2015.10.274

\section{General rights}

Copyright and moral rights for the publications made accessible in the public portal are retained by the authors and/or other copyright owners and it is a condition of accessing publications that users recognise and abide by the legal requirements associated with these rights.

- Users may download and print one copy of any publication from the public portal for the purpose of private study or research.

- You may not further distribute the material or use it for any profit-making activity or commercial gain

- You may freely distribute the URL identifying the publication in the public portal 


\section{Accepted Manuscript}

Classical molecular dynamics and quantum abs-initio studies on lithium-intercalation in interconnected hollow spherical nano-spheres of amorphous Silicon

A. Bhowmik, R. Malik, S. Prakash, T. Sarkar, M.D. Bharadwaj, S. Aich, S. Ghosh

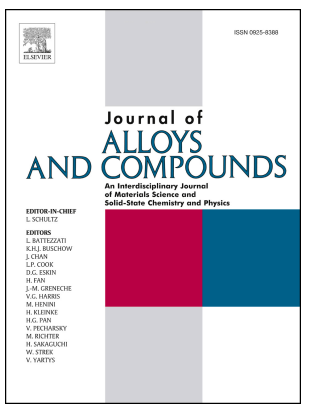

PII:

S0925-8388(15)31530-9

DOI:

10.1016/j.jallcom.2015.10.274

Reference: JALCOM 35829

To appear in: Journal of Alloys and Compounds

Received Date: 15 December 2014

Revised Date: 27 October 2015

Accepted Date: 29 October 2015

Please cite this article as: A. Bhowmik, R. Malik, S. Prakash, T. Sarkar, M.D. Bharadwaj, S. Aich, $\mathrm{S}$. Ghosh, Classical molecular dynamics and quantum abs-initio studies on lithium-intercalation in interconnected hollow spherical nano-spheres of amorphous Silicon, Journal of Alloys and Compounds (2015), doi: 10.1016/j.jallcom.2015.10.274.

This is a PDF file of an unedited manuscript that has been accepted for publication. As a service to our customers we are providing this early version of the manuscript. The manuscript will undergo copyediting, typesetting, and review of the resulting proof before it is published in its final form. Please note that during the production process errors may be discovered which could affect the content, and all legal disclaimers that apply to the journal pertain. 


\section{Classical molecular dynamics and quantum abs-initio studies on lithium-intercalation in interconnected hollow spherical nano- spheres of amorphous Silicon}

A. Bhowmik ${ }^{1,4}$, R. Malik ${ }^{2}$, S. Prakash ${ }^{3}$, T. Sarkar ${ }^{4}$, M. D. Bharadwaj ${ }^{4}$, S. Aich $^{2}$ and S. Ghosh $^{2 *}$

${ }^{1}$ Atomic Scale Modelling and Materials, Department of Energy Conversion and Storage, Technical University of Denmark, Rios Campus, Frederiksborgvej 399, DK4000 Roskilde, Denmark

${ }^{2}$ Department of Metallurgical and Materials Engineering, Indian Institute of Technology Kharagpur, Pin-721302, India

${ }^{3}$ Defense Metallurgical Research Laboratory, Hyderabad, India

${ }^{4}$ Center for Study of Science Technology and Policy, Bangalore-560094, India

${ }^{*}$ Corresponding author, e-mail: sudipto@metal.iitkgp.ernet.in

Keywords: amorphous, nano-glass, atomic density, lithium intercalation, cyclability

\section{Abstract}

A high concentration of lithium, corresponding to charge capacity of $\sim 4200 \mathrm{mAh} / \mathrm{g}$, can be intercalated in silicon. Unfortunately, due to high intercalation strain leading to fracture and consequent poor cyclability, silicon cannot be used as anode in lithium ion batteries. But recently interconnected hollow nano-spheres of amorphous silicon have been found to exhibit high cyclability. The absence of fracture upon lithiation and the high cyclability has been attributed to reduction in intercalation stress due to hollow spherical geometry of the silicon nano-particles. The present work argues that the hollow spherical geometry alone cannot ensure the absence of fracture. Using classical molecular dynamics and density functional theory based simulations; satisfactory explanation to the absence of fracture has been explored at the atomic scale.

\section{Introduction}

In commercial lithium ion batteries, graphitic carbon has been used as an anode material because of high discharge voltage, high cycle life and low cost. The available capacity of graphitic carbon is approaching near the theoretical value $\left(370 \mathrm{mAhg}^{-1}\right)$ [1]. In order to improve capacity of lithium ion secondary battery, silicon, instead of graphitic carbon is explored as an anode material because of its high theoretical capacity $\left(4200 \mathrm{mAhg}^{-1}\right)$, which 
corresponds to $\mathrm{Li}_{22} \mathrm{Si}_{5}$ formation [2, 3]. The theoretical capacity of silicon is 11 times higher than that of the graphitic carbon. Unfortunately, lithiation-de-lithiation in silicon is associated with large volume change which causes cracking of silicon leading to poor cycle life $[4,5]$. Graphite anodes use particles in the size range of 15-20 microns. If silicon particles of the same size are used instead of graphite, anode will fail within few cycles due to the fracture.

One of the promising ways to reduce the mechanical stress and therefore to increase the cycle life, is reduction of the particle size to nano-meter range. The same has been demonstrated in several publications [6-8], which show that with nano-scale materials it is possible to reach capacities up to $1700 \mathrm{mAh} / \mathrm{g}$, together with reduced fading. Additionally, adding carbon in the form of nano-silicon/carbon composites improves the stability significantly [9]. However, compared to common graphite electrodes, such materials still suffer from a relatively low cycle life and high fading. In contrast, composite electrodes based on nano-silicon inclusions in carbon aero gel were shown by Wang et al. to offer a stable charge capacity of $1450 \mathrm{mAh} / \mathrm{g}$ [10]. The same group also prepared a promising highcapacity composite electrode by ball-milling, but these electrodes still suffer from relatively high fading [11]. In the past, attempts were made to limit the amount of lithium inserted into the silicon and thus reducing the volume expansion [12]. This approach can offer relatively higher number of cycles with low capacity fading but compromises on capacity utilization.

Recently, Yao et al.[13] have found that interconnected hollow nano-spheres of amorphous silicon is a potential candidate for anode, having better cycle life and considerable capacity retention up to 700 cycles. This was attributed to the fact that the maximum tensile stress during lithiation is significantly lower for a hollow sphere as compared to a solid sphere. Thus the interconnected hollow nano-spheres are capable of accommodating large volume expansion without fracture. Considering poor fracture toughness of silicon [14], additional factors responsible for the high cyclability need to be explored. Yi Chi et. al proposed a new hierarchical structure of silicon anode which is of the shape of a pomegranate where the nano-particles of silicon is encapsulated by a conductive layer of carbon which in turn resulting in superior cyclability, high columbic efficiency and volumetric capacity [15], because of the sufficient void space created for expansion and contraction during lithium intercalation. Similar objective of accommodating volume expansion by creating void space in different forms such as hollow core shell, nonporous microspheres, hollow double-walled nano-tubes and hollow yolk-shell are addressed in various publications [16-22].

Classical molecular dynamics simulations, carried out in the present work, reveal significantly lower atomic density in interconnected hollow nano-spheres of amorphous silicon as compared to that of bulk amorphous silicon. Subsequent simulations which are based on density functional theory suggest that the reduction in atomic density results in significant decrease in the lithiation strain and smaller band-gap in the lithiated amorphous silicon. These, in turn, lead to high fracture toughness and good cyclability. Thus high cyclability in interconnected hollow nano-spheres of amorphous silicon, observed by Yao et al. [13], can be attributed to its lower atomic density. The phenomenon of reduction in atomic density of amorphous materials when the particle size is reduced to nano-range was first discovered by Gleiter [23]. Classical molecular dynamics simulations on $\mathrm{Cu}-\mathrm{Ti}$ [23] and $\mathrm{Cu}-$ $\mathrm{Zr}$ [24] amorphous systems and experimental measurements in other systems like Sc-Fe [25] have revealed that the lowering in atomic density is due to diffusion of free volume from interfaces formed between glassy nano-particles. 


\section{Simulation Methods}

\subsection{Molecular Dynamics Methodology}

All the computations are performed on the LAMMPS platform [26] using Stilinger-Weber (SW)[27] potential for silicon. Diamond cubic crystalline structures of silicon have been generated in simulation boxes of 3 different sizes, viz. i) $30 \AA \times 30 \AA \times 30 \AA$ (ii) $60 \AA \times 60 \AA$ $\times 60 \AA$ and (iii) $100 \AA \times 100 \AA \times 100 \AA$. Periodic boundary conditions in all three directions were applied to the systems. NPT ensemble was applied using Noose-hover algorithm. The system was heated to $2000 \mathrm{~K}$ (above $1687 \mathrm{~K}$, the melting point of pure silicon) to melt it completely and then, quenched to form amorphous silicon structure. During simulation the heating rate was $1.7 \mathrm{~K} \mathrm{ps}^{-1}$ while the cooling rate varied from $121.4 \mathrm{Kps}^{-1}$ to $425 \mathrm{Kps}^{-1}$. Nano-shell of amorphous silicon was extracted out of the block shaped amorphous silicon for further simulations. Table 1 gives the radii and centers of the spherical cavities within nano-spheres, which were enclosed in the cubic simulation boxes. In each case the system was allowed to equilibrate at $300 \mathrm{~K}, 750 \mathrm{~K}$ and $1200 \mathrm{~K}$ under atmospheric pressure for $0.2 \mathrm{~ns}$. In all the classical molecular dynamics simulations the time-step was equal to $\mathbf{0 . 0 0 2}$ ps.

Table 1: Dimensions of spheres of amorphous silicon having cavities

Computation of local density was carried out by moving a cubic sampling region, having dimensions of $5 \AA$ × $5 \AA$ × $5 \AA$ and having edges parallel to the edges of the simulation box, from one corner to the opposite corner of the simulation box. The movement of the sampling region within the simulation box was carried out in the following manner.

(a)A corner of the sampling region, in its starting configuration, coincided with that of the simulation box.

(b) The corner of the sampling region was displaced from (0 $\AA$, $0 \AA, 0 \AA)$ to (95 $\AA$, $95 \AA$, $95 \AA$ ) by increasing the $x, y$ and $z$ coordinates from 0 to $95 \AA$ in increments of $2.5 \AA$, using nested loops.

In this manner, the entire region within the simulation box is systematically covered and the sampling box does not step outside the simulation box.

For each of the positions of the cubic sampling region, the number of Si atoms within the sampling region was found out based on atomic coordinates. The number of 
atoms lying within the sampling region divided by the volume of the sampling region, i.e., 25.0 A 3 gives the atomic density corresponding to the center of the sampling region. This information was plotted as contour. The average atomic density was computed by eliminating regions with zero atomic densities and those regions where density drastically dropped to low value. These are the computed values in sampling regions, which are adjacent to sampling regions having zero atomic density.

\subsection{Density Functional Theory (DFT) Based Methodology}

Eight different atomic configurations of amorphous silicon were obtained in the following manner.

(1) Amorphous structures (having different atomic densities) were generated by carrying out classical MD simulation of annealing of nano-shells at different temperatures.

(2) Subsequently several10 $\AA$ × $10 \AA$ × $10 \AA$ cubic sub-cells were from these structures.

These configurations, hereafter referred to as I, II, III, IV, V, VI, VII and VIII had different number of atoms and different atomic densities. They were used for DFT studies on (a) volume expansion accompanying lithium insertion and (b) electronic structure resulting from the lithium insertion. For DFT simulations, model test cells were first relaxed for atomic positions and then for both cell parameters and atomic positions. Lithium insertion was modeled by adding 27 lithium atoms at uniform grid points $(3 \times 3 \times 3)$ inside the simulation boxes. After inserting the lithium atoms in the four configurations, the lithium atoms were first relaxed, keeping the silicon atoms fixed. Subsequently the silicon atoms were allowed to relax along with the lithium atoms. Finally, the cell parameters were optimized to get overall pressure $<0.1 \mathrm{k}$ bar (Error! Reference source not found.1).The DFT calculations were performed using projector augmented wave (PAW)[28] method with GGA functional (PBE type [29]) as implemented in VASP [30]. $450 \mathrm{eV}$ was assigned as the wave function cutoff and Brillouin zone was sampled with $2 \times 2 \times 2$ k-point mesh.

Formation energy with respect to bulk crystalline silicon, of different amorphous silicon configuration is tabulated in Table 2. Amorphous Si being metastable, formation energy is positive and that for different configurations are quite comparable

Table 2: Formation energy of different structures under consideration using DFT in this study 
The current approach is different from that adopted by Chevrier and Dahn [31]. They had used a portion of pre-computed amorphous Si structure. Li atoms were inserted in the structure one at a time and each insertion were followed by relaxation of the structure. Any insertion of $\mathrm{Li}$ atom was done at a point having the maximum distance from its nearest neighboring atom and the subsequent relaxation was subjected to a constraint, namely, the increase in the volume of the cell as a result of intercalation of single $\mathrm{Li}$ is fixed. As our aim was to study variability of volume increment, this method is not appropriate for our study.

Rohrer and Albe [32] took larger simulation cell. Their starting structure was crystalline Si and using DFT based molecular dynamics they showed the structural changes occurring during the $\mathrm{Li}$ intercalation and de-intercalation. Their work has led to important conclusion that poor cycle ability occurs due to phase separation that accompanies the massive expansion and contraction during the intercalation and deintercalation, respectively. Like Rohrer and Albe [32], large enough simulation cells have been taken and $\mathrm{Li}$ atoms have been randomly inserted in the present study. However, DFT-based molecular dynamics has not been used here, as there was a need to sample a larger number of metastable structures with varying atomic densities to study the effect of atomic density on volume expansion during $\mathbf{~} i$ intercalation. Further, to maximize the chances of getting stable structures, after starting from a random distribution of $\mathrm{Li}$ atoms, the $\mathrm{Li}$ to $\mathrm{Si}$ ratio was mostly varied between 0.5 and 0.7 . Interestingly, Kim et al. [33] found good stability of crystalline phase for percentage of lithiation atom varying between 0.65 and 0.75 .This lithiation level is 2.33 by our definition of lithiation level, thus significantly higher than our models. At higher lithiation level, crystalline phase is expected to be stable. Comprehensive work on electronic and vibration properties of crystalline phases were done by Chevrier et al. [37].

While being computationally less demanding, regular GGA functional (PBE) underestimates band gap significantly and the density of states (DOS) plot do not show proper band gap. Therefore we have performed the DOS calculations using PBE0 hybrid exchange-correlation functional. While PBE functional is known to severely underestimate band gap, it is fairly accurate in predicting structure for materials involving $s$ and $p$ block elements like lithium and silicon, while being much less computationally expensive than PBEO functional. Therefore, we studied structure using PBE functional and calculated electronic structure using PBEO functional.

A grid-based Bader code[34] was used to analyze the Bader charges of atoms in lithiated silicon. In this method the simulation box was divided into several atomic zones such that the zone boundaries had zero electron density gradients at every point. The net charge transfer from lithium to silicon atoms was computed using effective Bader charge on lithium atoms. 
Figure1: Lithiated and pristine configuration for higher (50 atoms) and lower density (43 atoms) amorphous Si with bond connectivity. (a) and (c) show structures for high density and low density amorphous silicon configurations before lithiation. (b) and (d) show structures for high density and low density amorphous silicon configurations after lithiation. Lower connectivity and higher porosity in low density silicon

\section{Results and Discussion}

Atomic density of interconnected hollow nano-spheres of amorphous silicon, computed using classical MD simulations has been reported in Section 3.1. The computed atomic density in hollow nano-spheres was found to be lower than that in bulk amorphous silicon. DFT simulations for computing the volume expansion accompanying lithiation were carried out for eight different configurations of amorphous silicon having different atomic densities. Section 3.2 reports about the volume expansion during lithiation. The lowering in atomic density had a significant effect on the volume expansion accompanying lithiation as well as on the electronic state. The density of states (DOS) for two configurations, in both de-lithiated and lithiated states, are reported in Section 3.3. This section also reports charge transfer from lithium to silicon.

\subsection{Atomic density in interconnected hollow nano-spheres of amorphous silicon}

Figure 2 shows atomic density contour of bulk amorphous Si at $300 \mathrm{~K}$, generated according to the procedure described in Section 2.1. The nano-shells which have been annealed at different temperatures, subjected to periodic boundary condition, have been cut out from this structure. Figure 3 and Figure 4 show the atomic density contour in nano-shells, initially having the same structure as bulk amorphous $\mathrm{Si}$ at $300 \mathrm{~K}$, after annealing at $300 \mathrm{~K}$ and $750 \mathrm{~K}$ respectively. The contour pattern does not change as a result of annealing. However there are other effects of annealing, which are as follows. 
Figure 2: Contour plot of atomic density of bulk amorphous Si at $300 \mathrm{~K}$

Figure 3shows the contour of atomic density in amorphous silicon obtained after annealing a periodic array of nano-shells (shell thickness $=25 \AA$ ) at $300 \mathrm{~K}$. The cavity of silicon nanoshell was more or less stable at $300 \mathrm{~K}$ as depicted in Figure 3 . Volume expansion was negligible at this temperature. However, the scenario was different at higher temperatures. As can be seen in Figure 4, at higher temperature $(750 \mathrm{~K})$ the thickness of shell increased and the cavity-size decreased due to diffusion of atoms towards the cavity or diffusion of free volume into the shell. The diffusion occurred over a short period of $40 \mathrm{ps}$. Due to that process the atomic density within the shell decreased, as evident from the data reported in Table 2. Table 3 reports the computed average atomic density within the shell region. The decrease was significant at $750 \mathrm{~K}$ and $1200 \mathrm{~K}$ (Table 3). 
Nano-particles have extremely high surface area to volume ratio (S), which, in the case of a nano-shell is given by

$$
S=\frac{4 \pi r^{2}+4 \pi(r+\delta)^{2}}{4 / 3 \pi(r+\delta)^{3}-4 / 3 \pi r^{3}}
$$

Or

$\mathrm{S}=\frac{2 r^{2}+2 r \delta+\delta^{2}}{1 / 3 \delta^{3}+r^{2} \delta+\delta^{2} r}$

Substituting $\delta=c r$, where $\delta$ and $c$ are shell thickness and shell thickness to radius ratio respectively, we get

$S=\frac{\frac{1}{c r}\left(\frac{2}{c^{2}}+\frac{2}{c}+1\right)}{\frac{1}{3}+\frac{1}{c^{2}}+\frac{1}{c}}$

Equation (2) suggests that the ratio reduces with increasing $c$. Thus, the shrinkage of cavity or increase in $c$ at $750 \mathrm{~K}$ was driven by lowering of free energy due to reduction in surface area. On the other hand, the observed lowering of atomic density would increase the energy per atom and hence would oppose the increase in $c$. In the present study the $c$ increased to an equilibrium value, suggesting that the two forces are balanced.

This shrinkage of cavity and reduction of atomic density within the nano-shells occur in extremely short duration due to high self-diffusivity of silicon in its amorphous form, which are many orders of magnitude higher than that in crystalline silicon. At $750 \mathrm{~K}$ the drop in the average atomic density within the nano-shells is $\sim 15 \%$. On the other hand, at $300 \mathrm{~K}$, the decrease in the atomic density of the nano-shell is much lower (for duration of $\mathbf{0 . 2} \mathbf{n s ) , ~ d u e ~ t o ~ s i g n i f i c a n t l y ~ l o w e r ~ s e l f - d i f f u s i v i t y ~ o f ~ S i . ~ T h u s , ~}$ considering the following facts

(i) The driving force to reduce surface area at the cost of decrease in atomic density is present above $300 \mathrm{~K}$, as suggested by the results shown in Figures 3-4 and Table 3.

(ii) The kinetics was fast enough at $750 \mathrm{~K}$, leading to $\sim 15 \%$ reduction in average atomic density of the nano-shells within less than 0.2 ns. Kinetics becomes sluggish as the temperature is reduced to $300 \mathrm{~K}$ (Figures $3-4$ and Table 3).

(iii) Yao et al. [13] deposited the amorphous $\mathrm{Si}$ at $\sim 750 \mathrm{~K}$ and subsequently it was cooled down. The deposition was done over a period of time $(20 \mathrm{~min})$ which is orders of magnitude higher than $0.2 \mathrm{~ns}$.

it can be theoretically concluded that atomic density in the interconnected hollow nano-spheres of amorphous silicon, deposited by Yao et al.[13], was at least $15 \%$ lower (see Table 3 ) than that in bulk amorphous silicon. 
There are two kinds of cavities in the interconnected hollow nano-spheres: (i) hollow region inside a nano-sphere and (ii) inter particle void region. It must be noted that the shrinkage of the latter was more prominent.

Figure 3: Contour plot of atomic density at 300K showing stability of the nano-shell 
Figure 4: Contour plot of atomic density at $750 \mathrm{~K}$ showing stability of the nano-shell

Table 3: Average density of bulk and nano-shell amorphous silicon at different temperatures

\subsection{Volume expansion as a result of lithiation}

Volume change associated with $\mathrm{Li}$ insertion was studied using DFT based simulations. As a result of the $\mathrm{Li}$ insertion, simulation boxes expanded for all the configurations. The percentage volume expansion (hereafter referred to \%VE) varied from $26.6 \%$ to $109.8 \%$. Table 4 reports \%VE for the eight different structures, having different atomic densities. It can be seen that the \%VE depends, not only on the pre-lithiation atomic density (hereafter referred to as PLAD) or pre-lithiation density (PLD), but also on the extent of $\mathrm{Li}$ insertion. Therefore, in order to study the effect of PLAD (or PLD) on the volume expansion, the \%VE was normalized by the degree of lithiation or the $\mathrm{Li}$ to $\mathrm{Si}$ ratio(x). In other words the percentage volume expansion per degree of lithiation (\%VE divided by $x$ and hereafter referred to as \%VE $\mathrm{E}_{\mathrm{x}}$ ) was computed and its variation with the pre-lithiation density or PLD is reported in Table 4. The same has been plotted in Figure 5. \%VE $\mathrm{x}_{\mathrm{x}}$ significantly increased with PLD. Based on the best fit plots in Figure 5 the following important conclusions can be drawn.

(1) The variation of $\% \mathrm{VE}_{\mathrm{x}}$ with PLD can be treated as linear.

(2) Fluctuation around best fit line through data points in Figure 5 is there. This is expected because there are subtle differences between any two glassy structures, apart from the atomic density.

(3) The \%VE $E_{x}$ versus PLD slope reduces with the degree of lithiation or $\mathbf{x}$.

(4) For $x$ varying in the range: 0.16 to $0.186,8.53 \%$ reduction (from $2.437 \mathrm{gm} \mathrm{cm}^{-3}$ to $2.29 \mathrm{gm} \mathrm{cm}^{-3}$ ) in PLD resulted in $67.7 \%$ decrease (from $75 \%$ to $7.3 \%$ ) in the $\% \mathrm{VE}_{\mathrm{x}}$. Extrapolating the best fit line to $\sim 15 \%$ reduction in the PLD (as predicted 
using classical MD simulation and reported in Section 3.1) $\sim 119 \%$ reduction in the $\% V E_{x}$ is expected.

(5) For $x$ varying in the range: $0.54-0.711,8.53 \%$ reduction (from $2.437 \mathrm{gm} \mathrm{cm}^{-3}$ to $2.29 \mathrm{gm} \mathrm{cm}^{-3}$ ) in PLD resulted in $\sim 26 \%$ decrease (from $\sim 71 \%$ to $\sim 45 \%$ ) in the $\% \mathrm{VE}_{\mathrm{x}}$. Extrapolating the best fit line to $\sim 15 \%$ reduction in the PLD (as predicted using classical MD simulation and reported in Section 3.1 ) $\sim 45.7 \%$ reduction in the $\% \mathrm{VE}_{\mathrm{x}}$ is expected.

(6) For $x$ varying in the range: 1.28-1.6, $8.53 \%$ reduction (from $2.437 \mathrm{gm} \mathrm{cm}^{-3}$ to $2.29 \mathrm{gm} \mathrm{cm}^{-3}$ ) in PLD resulted in $\sim 11 \%$ decrease (from $\sim 74 \%$ to $\sim 63 \%$ in the $\% \mathrm{VE}_{\mathrm{x}}$. Extrapolating the best fit line to $\sim 15 \%$ reduction in the PLD (as predicted using classical MD simulation and reported in Section 3.1) $19.8 \%$ reduction in the $\% V E_{x}$ is expected.

The prediction of stress by Yao et al. [13] was purely based on the geometrical aspect at the mesoscopic scale. Based on the geometrical considerations they predicted a drop in lithiation stress from $>400 \mathrm{MPa}$ to $75 \mathrm{MPa}$. In the present study an additional phenomenon of lowering of atomic density has been shown to further reduce the lithiation strain and stress to significant extents, especially at early stage of lithiation.

Table 4: Density, volume, percentage volume expansion, degree of lithiation and percentage volume expansion per degree of lithiation of different configurations of amorphous silicon 
Figure 5: Variation of percentage volume expansion per degree of lithiation with density of initial amorphous Si

To validate that the structure under consideration are representative, we calculated the lithiation energies computed from bulk lithium reference (Table 5). As the lithiation energies are comparable, we can establish our inference based on these set of structures.

Table 5: Average lithiation energy for different structures 


\subsection{Effect of reduced atomic density on electronic structure of lithiated amorphous silicon}

Density functional theory (DFT) based simulations revealed that the electronic structure is modified significantly upon lithium insertion. Fig. 6 shows the DOS of two amorphous $\mathrm{Si}$ configurations, both before and after lithiation, obtained using hybrid density functional (PBE0). Band gap decreases due to $\mathrm{Li}$ insertion, leading to metallic system with high Li content. The variation in band gap between different tests cells arise from vastly different coordination for $\mathrm{Si}$ atoms. As lithium valence electrons are transferred to Si orbital, electronic band gap diminishes. Similar effects have been studied by Kim et. al [33]. Lithium atoms behave as ionic species in all test cells. Irrespective of the model system and lithiation level, the charged state of Li remains same $(\sim+0.8)$ as calculated from Bader charges [Table 6 ]. While our results do not match with the results obtained by Chevrier et al. [35] but our results, agree well with the more recent work ( 0.83 e per Li atom) by Moon et al. [36].

Pre-lithiation atomic density had significant influence on DOS of both pre-lithiated and lithiated structures for low degree of lithiation. For low degree of lithiation, the band gap is significantly higher for structure with low pre-lithiation density. This suggests that atomic density also alters the electron distribution, which is known to influence the fracture property. 
Figure 6: Electronic DOS of amorphous Si configuration 1 and 4 (unit of energy =eV) for different degrees of lithiation calculated using hybrid functional

Table 6: Amount of charge transfer from lithium to silicon atoms in different configurations

\section{Conclusions}

(a)Yao et al. [13], for the first time, synthesized interconnected hollow nano-spheres of amorphous silicon. The interconnected nano-spheres exhibit high Li holding capacity as well as high cyclability when used as anode material. Although they have attributed the high $\mathrm{Li}$ 
holding capacity and the high cycle ability to hollow geometry leading to significant lowering of intercalation stress, the present study identify another equally important mechanism behind lowering of intercalation stress.

(b) Classical molecular dynamics simulations using Stilinger-Weber (SW) [27] potential for silicon, reveal that the atomic density of interconnected hollow nano-spheres of amorphous silicon is significantly lower ( 15\%) than that of bulk amorphous silicon.

(c) It was found that the lowering of atomic density significantly reduced the intercalation strain or the volume expansion upon lithiation. The decrease in the lithiation strain, in turn decreased the lithiation stress. The volume expansion upon lithiation was estimated using density functional theory (DFT) approach.

(c) The lowering of atomic density also resulted in change of density of states (DOS) upon lithium intercalation. This also indicates possible shift to metallic character

(d) Significant reduction in the lithiation stress result in higher cycle ability in the interconnected hollow nano-spheres of amorphous silicon.

(e) Interconnected hollow nano-spheres of amorphous silicon are an example of nano-glass discovered by Gleiter and co-workers [23-25]. 


\section{References}

[1] J.M. Tarascon, M. Armand, Issues and challenges facing rechargeable lithium batteries, Nature 414 (2001)359-367.

[2] J.Y. Kwon, J.H. Ryu, S.M. Oh, Performance of electrochemically generated Li21Si5 phase for lithium-ion batteries, Electrochimica Acta 55 (2010) 8051-8055.

[3] H. Kim, C.Y. Chou, J.G. Ekerdt, G.S. Hwang, A Comparative First-Principles Study of the Structure, Energetics, and Properties of $\mathrm{Li}-\mathrm{M}(\mathrm{M}=\mathrm{Si}, \mathrm{Ge}, \mathrm{Sn})$ Alloys, The Journal of Physical Chemistry C 115 (2011) 20018-20026.

[4] G.B. Cho, M.G. Song, S.H. Bae, J.K. Kim, Y.J. Choi, H.J. Ahn, J.H. Ahn, K.K. Cho, K.W. $\mathrm{Kim}$, Surface-modified $\mathrm{Si}$ thin film electrode for $\mathrm{Li}$ ion batteries (LiFePO4/Si) by clusterstructured Ni under layer, Journal of Power Sources 189 (2009) 738-742.

[5] S.J. Lee, J.K. Lee, S.H. Chung, H.Y. Lee, S.M. Lee, H.K. Baik, Stress effect on cycle properties of the silicon thin-film anode, Journal of Power Sources 97-98 (2001) 191-193.

[6] H. Jung, M. Park, Y.G. Yoon, G.B Kim, S.K.Joo, Amorphous silicon anode for lithium-ion rechargeable batteries, Journal of Power Sources 115 (2003) 346-351.

[7] H. Li, X. Huang, L. Chen, Z. Wu, Y. Liang, A High Capacity Nano Si Composite Anode Material for Lithium Rechargeable Batteries, Electrochemical and Solid-State Letters 2 (1999) 547-549.

[8] B. Gao, S. Sinha, L. Fleming, O. Zhou, Alloy Formation in Nanostructured Silicon, Advanced Materials 13 (2001) 816-819.

[9] A.M. Wilson, J.R. Dahn, Lithium Insertion in Carbons Containing Nanodispersed Silicon, Journal of The Electrochemical Society 142 (1995) 326-332.

[10] G.X. Wang, J.H. Ahn, J. Yao, S. Bewlay, H.K. Liu, Nanostructured Si-C composite anodes for lithium-ion batteries, Electrochemistry communications 6 (2004) 689-692.

[11] G.X. Wang, J. Yao, H.K. Liu, Characterization of Nanocrystalline Si-MCMB Composite Anode Materials, Electrochemical and solid-state letters 7 (2004) A250-A253.

[12] M. Holzapfel, H. Buqa, L.J. Hardwick, M. Hahn, A. Würsig, W. Scheifele, P. Novák, R. Kötz, C. Veit, F.M. Petrat, Nano silicon for lithium-ion batteries, Electrochimica acta 52 (2006) 973-978. 
[13] Y. Yao, M.T. McDowell, I. Ryu, H. Wu, N. Liu, L. Hu, W.D. Nix, Y. Cui, Interconnected Silicon Hollow Nanospheres for Lithium-Ion Battery Anodes with Long Cycle Life, Nano letters 11 (2011) 2949-2954.

[14] S. Nakao, T. Ando, M. Shikida, K. Sato, Effect of temperature on fracture toughness in a single-crystal-silicon film and transition in its fracture mode, Journal of Micromechanics and Microengineering18 (2008) 015026.

[15] N. Liu, Z. Lu, J. Zhao, M.T. McDowell, H.W. Lee, W. Zhao, Y. Cui, A pomegranateinspired nanoscale design for large-volume-change lithium battery anodes, Nature Nanotechnology 9 (2014) 187-192.

[16] H. Wu, G. Chan, J. W. Choi, I. Ryu, Y. Yao, M.T. McDowell, S.W. Lee, A. Jackson, Y. Yang, L. Hu, Y. Cui, Stable cycling of double-walled silicon nanotube battery anodes through solid-electrolyte interphase control, Nature Nanotechnology 7 (2012) 310-315.

[17] C.K. Chan, H. Peng, G. Liu, K. Mcllwrath, X.F. Zhang, R.A. Huggins, Y. Cui, Highperformance lithium battery anodes using silicon nanowires, Nature Nanotechnology 3 (2008) 31-35.

[18] S. Chen, M.L. Gordin, R. Yi, G. Howlett, H. Sohn, D.Wang, Silicon core-hollow carbon shell nanocomposites with tunable buffer voids for high capacity anodes of lithium-ion batteries, Phys. Chem. Chem. Phys. 14 (2012) 12741-12745.

[19] X. Li, P. Meduri, X. Chen, W. Qi, M.H. Engelhard, W. Xu, F. Ding, J. Xiao, W. Wang, C. Wang, J.G. Zhang, J. Liu, Hollow core-shell structured porous Si-C nanocomposites for Liion battery anodes, Journal of Materials Chemistry 22 (2012) 11014-11017.

[20] H. Wua, Y. Cui, Designing nanostructured Si anodes for high energy lithium ion batteries, Nano Today 7 (2012) 414-429.

[21] Y.X. Yin, S. Xin, L.J. Wan, C.J. Li, Y.G. Guo, Electrospray Synthesis of Silicon/Carbon Nanoporous Microspheres as Improved Anode Materials for Lithium-Ion Batteries, J. Phys. Chem. C 115 (2011) 14148-14154.

[22] T.H. Hwang, Y.M. Lee, B.S. Kong, J.S. Seo, J.W. Choi, Electrospun Core-Shell Fibers for Robust Silicon Nanoparticle-Based Lithium Ion Battery Anodes, Nano Lett. 12 (2012) 802-807.

[23] H. Gleiter, Our thoughts are ours, their ends none of our own: Are there ways to synthesize materials beyond the limitations of today?, Acta Materialia 56 (2008) 5875-5893.

[24] D. Sopu, K. Albe, Y. Ritter, H. Gleiter, From nanoglasses to bulk massive glasses, Applied Physics Letters 94 (2009) 191911.

[25] J.X. Fang, U. Vainio, W. Puff, R. Würschum, X.L. Wang, D. Wang, M. Ghafari, F. Jiang, J. Sun, H. Hahn, H. Gleiter, Atomic Structure and Structural Stability of Sc75Fe25 Nanoglasses, Nano Lett. 12 (2012) 458-463.

[26] S. Plimpton, Fast Parallel Algorithms for Short-Range Molecular Dynamics, Journal of Computational Physics 117 (1995) 1-19. 
[27] F.H. Stillinger, T.A. Weber, Computer simulation of local order in condensed phases of silicon, Physical Review B 31 (1985) 5262.

[28] P.E. Blöchl, Projector augmented-wave method, Physical Review B 50 (1994) 17953.

[29] J.P. Perdew, K. Burke, M. Ernzerhof, Generalized Gradient Approximation Made Simple, Physical review letters 77 (1996) 3865.

[30] G. Kresse, J. Furthmüller, Efficient iterative schemes for ab initio total-energy calculations using a plane-wave basis set, Physical Review B 54 (1996) 11169.

[31] V.L. Chevrier, J.R. Dahn, First Principles Model of Amorphous Silicon Lithiation, Journal of The Electrochemical Society 156 (2009) A454-A458.

[32] J. Rohrer, K. Albe, Insights into Degradation of $\mathrm{Si}$ Anodes from First-Principle Calculations, The Journal of Physical Chemistry C 117 (2013)18796-18803.

[33] H. Kim, C.Y. Chou, J.G. Ekerdt, G.S. Hwang, Structure and Properties of Li-Si Alloys:A First-Principles Study, The Journal of Physical Chemistry C 115 (2011) 2514-2521.

[34] W. Tang, E. Sanville, G. Henkelman, A grid-based Bader analysis algorithm without lattice bias, Journal of Physics-Condensed Matter 21 (2009) 084204.

[35] V.L. Chevrier, J.R. Dahn, First Principles Studies of Disordered Lithiated Silicon, Journal of The Electrochemical Society 157 (2010) A392-A398.

[36] Janghyuk Moon, Byeongchan Lee, Maenghyo Cho, Kyeongjae Cho, Ab initio and kinetic Monte Carlo simulation study of lithiation in crystalline and amorphous silicon, Journal of Power Sources 272 (2014) 1010-1017.

[37] Chevrier, V. L., Zwanziger, J. W. \& Dahn, J. R. First principles study of Li-Si crystallinephases: Charge transfer, electronic structure, and lattice vibrations. J. Alloys Compd. 496, 25-36 (2010). 


\begin{tabular}{|c|c|c|c|}
\hline $\begin{array}{c}\text { Dimension of simulation } \\
\text { box }(\AA \AA \AA \AA \AA \AA \AA\end{array}$ & $\begin{array}{c}\text { Coordinates of centre of sphere and cavity } \\
\text { with respect to simulation box }(\AA, \AA, \AA)\end{array}$ & $\begin{array}{l}\text { Radius of } \\
\text { sphere }(\AA)\end{array}$ & $\begin{array}{l}\text { Radius of } \\
\text { cavity }(\AA)\end{array}$ \\
\hline $30 \times 30 \times 30$ & $(15,15,15)$ & 15 & 5 \\
\hline $60 \times 60 \times 60$ & $(30,30,30)$ & 30 & 15 \\
\hline $100 \times 100 \times 100$ & $(50,50,50)$ & 50 & 25 \\
\hline
\end{tabular}

Table 1: Dimensions of spheres of amorphous silicon having cavities

\begin{tabular}{|l|l|l|}
\hline Configuration & No. of atoms & $\begin{array}{l}\text { Formation energy } \\
\text { per Si atom (eV) }\end{array}$ \\
\hline 1 & 40 & 0.285 \\
\hline 2 & 43 & 0.300 \\
\hline 3 & 46 & 0.289 \\
\hline 4 & 50 & 0.329 \\
\hline 5 & 38 & 0.298 \\
\hline 6 & 45 & 0.323 \\
\hline 7 & 47 & 0.355 \\
\hline 8 & 48 & 0.316 \\
\hline
\end{tabular}

Table 2: Formation energy of different structures under consideration using DFT in this study

\begin{tabular}{|c|c|c|c|}
\hline \multirow{2}{*}{ Amorphous silicon structure } & \multicolumn{3}{|c|}{ Average Density $\left(\mathrm{gm}^{-\mathrm{cm}^{-3}}\right)$} \\
\cline { 2 - 4 } & $300 \mathrm{~K}$ & $750 \mathrm{~K}$ & $1200 \mathrm{~K}$ \\
\hline Bulk & 2.46 & --- & --- \\
\hline Nano-shell & 2.33 & 2.04 & 1.77 \\
\hline
\end{tabular}

Table 3: Average density of bulk and nano-shell amorphous silicon at different temperatures 


\begin{tabular}{|c|c|c|c|c|c|c|c|c|}
\hline \multicolumn{9}{|c|}{ Low level of lithiation: $8 \mathrm{Li}$ atoms per test cell of amorphous $\mathrm{Si}$} \\
\hline \multirow[b]{2}{*}{ Configuration } & \multirow{2}{*}{$\begin{array}{l}\text { No. of } \\
\text { silicon } \\
\text { atoms }\end{array}$} & \multicolumn{2}{|c|}{ Before lithiation } & \multicolumn{2}{|c|}{ After lithiation } & \multirow{2}{*}{$\begin{array}{l}\text { Percentage } \\
\text { Volume } \\
\text { expansion } \\
(\% \mathrm{VE})\end{array}$} & \multirow{2}{*}{$\begin{array}{c}\text { Degree } \\
\text { of } \\
\text { lithiation } \\
\quad(x \text { in } \\
\left.\mathrm{Li}_{\mathrm{x}} \mathrm{Si}\right)\end{array}$} & \multirow{2}{*}{$\begin{array}{c}\text { Percentage } \\
\text { Volume } \\
\text { expansion } \\
\text { per degree } \\
\text { of lithiation } \\
\left(\% \mathrm{VE}_{\mathrm{x}}\right)\end{array}$} \\
\hline & & $\begin{array}{l}\text { Volume } \\
\left(\AA^{3}\right)\end{array}$ & $\begin{array}{c}\text { Density } \\
\left(\mathrm{gm} / \mathrm{cm}^{3}\right) / \\
\text { PLD }\end{array}$ & $\begin{array}{l}\text { Volume } \\
\left(\AA^{3}\right)\end{array}$ & $\begin{array}{l}\text { Density } \\
\left(\mathrm{gm} / \mathrm{cm}^{3}\right)\end{array}$ & & & \\
\hline 2 & 43 & 896.8 & 2.229 & 909.0 & 2.308 & 1.36 & 0.186 & 7.31 \\
\hline 4 & 50 & 953.7 & 2.437 & 1068.33 & 2.269 & 12.0 & 0.16 & 75.0 \\
\hline \multicolumn{9}{|c|}{ Medium level of lithiation: $27 \mathrm{Li}$ atoms per test cell of amorphous $\mathrm{Si}$} \\
\hline \multirow[b]{2}{*}{ Configuration } & \multirow{2}{*}{$\begin{array}{l}\text { No. of } \\
\text { silicon } \\
\text { atoms }\end{array}$} & \multicolumn{2}{|c|}{ Before lithiation } & \multicolumn{2}{|c|}{ After lithiation } & \multirow{2}{*}{$\begin{array}{l}\text { Percentage } \\
\text { Volume } \\
\text { expansion } \\
\text { (\%VE) }\end{array}$} & \multirow{2}{*}{$\begin{array}{c}\text { Degree } \\
\text { of } \\
\text { lithiation } \\
\quad(x \text { in } \\
\left.\mathrm{Li}_{\mathrm{x}} \mathrm{Si}\right)\end{array}$} & \multirow{2}{*}{$\begin{array}{l}\text { Percentage } \\
\text { Volume } \\
\text { expansion } \\
\text { per degree } \\
\text { of lithiation } \\
\left(\% \mathrm{VE}_{\mathrm{x}}\right)\end{array}$} \\
\hline & & $\begin{array}{l}\text { Volume } \\
\left(\AA^{3}\right)\end{array}$ & $\begin{array}{c}\text { Density } \\
\left(\mathrm{gm} / \mathrm{cm}^{3}\right) / \\
\text { PLD }\end{array}$ & $\begin{array}{l}\text { Volume } \\
\left(\AA^{3}\right)\end{array}$ & $\begin{array}{l}\text { Density } \\
\left(\mathrm{gm} / \mathrm{cm}^{3}\right)\end{array}$ & & & \\
\hline 1 & 40 & 803.2 & 2.315 & 1096.7 & 1.985 & 36.5 & 0.675 & 54.0 \\
\hline 2 & 43 & 896.8 & 2.229 & 1159.0 & 1.999 & 29.2 & 0.628 & 46.5 \\
\hline 3 & 46 & 905.2 & 2.326 & 1200.5 & 2.046 & 32.6 & 0.587 & 55.5 \\
\hline 4 & 50 & 953.7 & 2.437 & 1312.6 & 2.014 & 37.6 & 0.540 & 69.6 \\
\hline 5 & 38 & 782.8 & 2.264 & 1077.3 & 1.934 & 37.6 & 0.711 & 52.7 \\
\hline 6 & 45 & 920.1 & 2.281 & 1225 & 1.967 & 33.1 & 0.600 & 55.2 \\
\hline 7 & 47 & 919.2 & 2.385 & 1304.2 & 1.919 & 41.9 & 0.574 & 73.0 \\
\hline 8 & 48 & 968.6 & 2.311 & 1249.2 & 2.041 & 26.6 & 0.563 & 47.3 \\
\hline \multicolumn{9}{|c|}{ ligher level of lithiation: $64 \mathrm{Li}$ atoms per test cell of amorphous $\mathrm{Si}$} \\
\hline \multirow[b]{2}{*}{ Configuration } & \multirow{2}{*}{$\begin{array}{l}\text { No. of } \\
\text { silicon } \\
\text { atoms }\end{array}$} & \multicolumn{2}{|c|}{ Before lithiation } & \multicolumn{2}{|c|}{ After lithiation } & \multirow{2}{*}{$\begin{array}{l}\text { Percentage } \\
\text { Volume } \\
\text { expansion } \\
(\% \mathrm{VE})\end{array}$} & \multirow{2}{*}{$\begin{array}{c}\text { Degree } \\
\text { of } \\
\text { lithiation } \\
(\mathrm{x} \text { in } \\
\left.\mathrm{Li}_{\mathrm{x}} \mathrm{Si}\right)\end{array}$} & \multirow{2}{*}{$\begin{array}{l}\text { Percentage } \\
\text { Volume } \\
\text { expansion } \\
\text { per degree } \\
\text { of lithiation } \\
\left(\% \mathrm{VE}_{\mathrm{x}}\right)\end{array}$} \\
\hline & & $\begin{array}{c}\text { Volume } \\
\left(\AA^{3}\right)\end{array}$ & $\begin{array}{c}\text { Density } \\
\left(\mathrm{gm} / \mathrm{cm}^{3}\right) / \\
\text { PLD }\end{array}$ & $\begin{array}{l}\text { Volume } \\
\left(\AA^{3}\right)\end{array}$ & $\begin{array}{l}\text { Density } \\
\left(\mathrm{gm} / \mathrm{cm}^{3}\right)\end{array}$ & & & \\
\hline 1 & 40 & 803.2 & 2.315 & 1685.5 & 1.544 & 109.8 & 1.6 & 68.6 \\
\hline 2 & 43 & 896.8 & 2.229 & 1739.3 & 1.577 & 93.9 & 1.488 & 63.1 \\
\hline 4 & 50 & 953.7 & 2.437 & 1865 & 1.646 & 95.6 & 1.28 & 74.7 \\
\hline
\end{tabular}

Table 4: Density, volume, percentage volume expansion, degree of lithiation and percentage volume expansion per degree of lithiation of different configurations of amorphous silicon 


\begin{tabular}{|c|c|c|c|}
\hline Configuration & \multicolumn{3}{|c|}{} \\
\hline 1 & $8 \mathrm{ii}$ & $27 \mathrm{li}$ & $64 \mathrm{li}$ \\
\hline 2 & & -0.466 & -0.462 \\
\hline 3 & -0.646 & -0.567 & -0.462 \\
\hline 4 & & -0.517 & \\
\hline 5 & -0.795 & -0.629 & -0.495 \\
\hline 6 & & -0.532 & \\
\hline 7 & & -0.566 & \\
\hline 8 & & -0.627 & \\
\hline & & -0.570 & \\
\hline
\end{tabular}

Table 5: Average lithiation energy (in eV/Li atom) for different structures

\begin{tabular}{|c|c|c|c|}
\hline Configuration & $\begin{array}{l}\text { No. of silicon } \\
\text { atoms }\end{array}$ & $\begin{array}{c}\text { Average electron transferred from } \\
\text { each lithium atom }\end{array}$ & $\begin{array}{l}\text { Average electron transferred } \\
\text { to each silicon atom }\end{array}$ \\
\hline \multicolumn{4}{|c|}{ From calculations with $8 \mathrm{Li}$ atoms } \\
\hline$\underline{2}$ & 43 & 0.813 & $\underline{0.151}$ \\
\hline$\underline{4}$ & 50 & 0.835 & $\underline{0.134}$ \\
\hline \multicolumn{4}{|c|}{ From calculations with $27 \mathrm{Li}$ atoms } \\
\hline 1 & 40 & 0.815 & 0.55 \\
\hline 2 & 43 & 0.823 & 0.517 \\
\hline 3 & 46 & 0.826 & 0.485 \\
\hline 4 & 50 & 0.821 & 0.443 \\
\hline 5 & 38 & 0.821 & 0.584 \\
\hline 6 & 45 & 0.827 & 0.507 \\
\hline 7 & 47 & 0.828 & 0.456 \\
\hline 8 & 48 & 0.826 & 0.465 \\
\hline \multicolumn{4}{|c|}{ From calculations with $64 \mathrm{Li}$ atoms } \\
\hline 1 & 40 & 0.810 & 1.295 \\
\hline 2 & 43 & 0.806 & 1.20 \\
\hline 4 & 50 & 0.793 & 0.964 \\
\hline
\end{tabular}

Table 6: Amount of charge transfer from lithium to silicon atoms in different configurations 


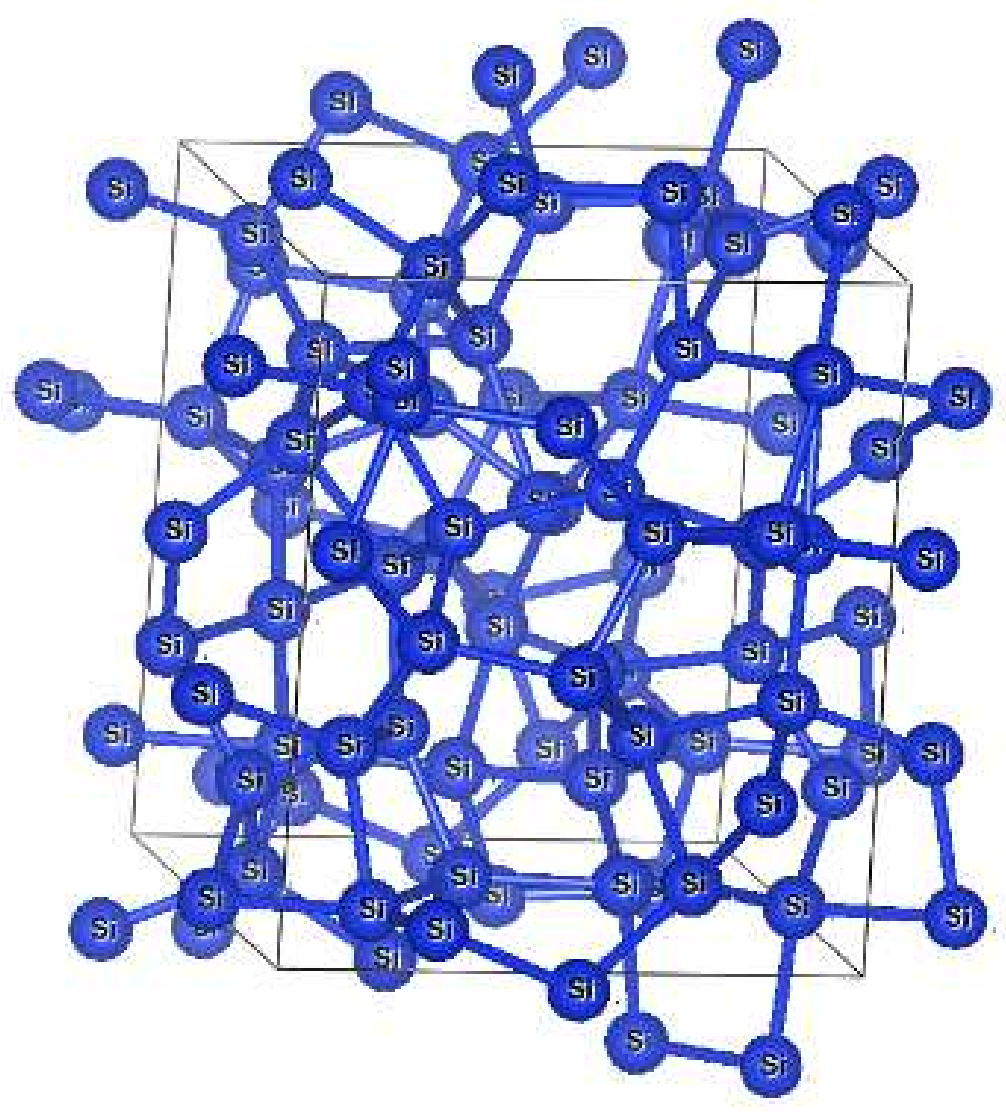

(a)

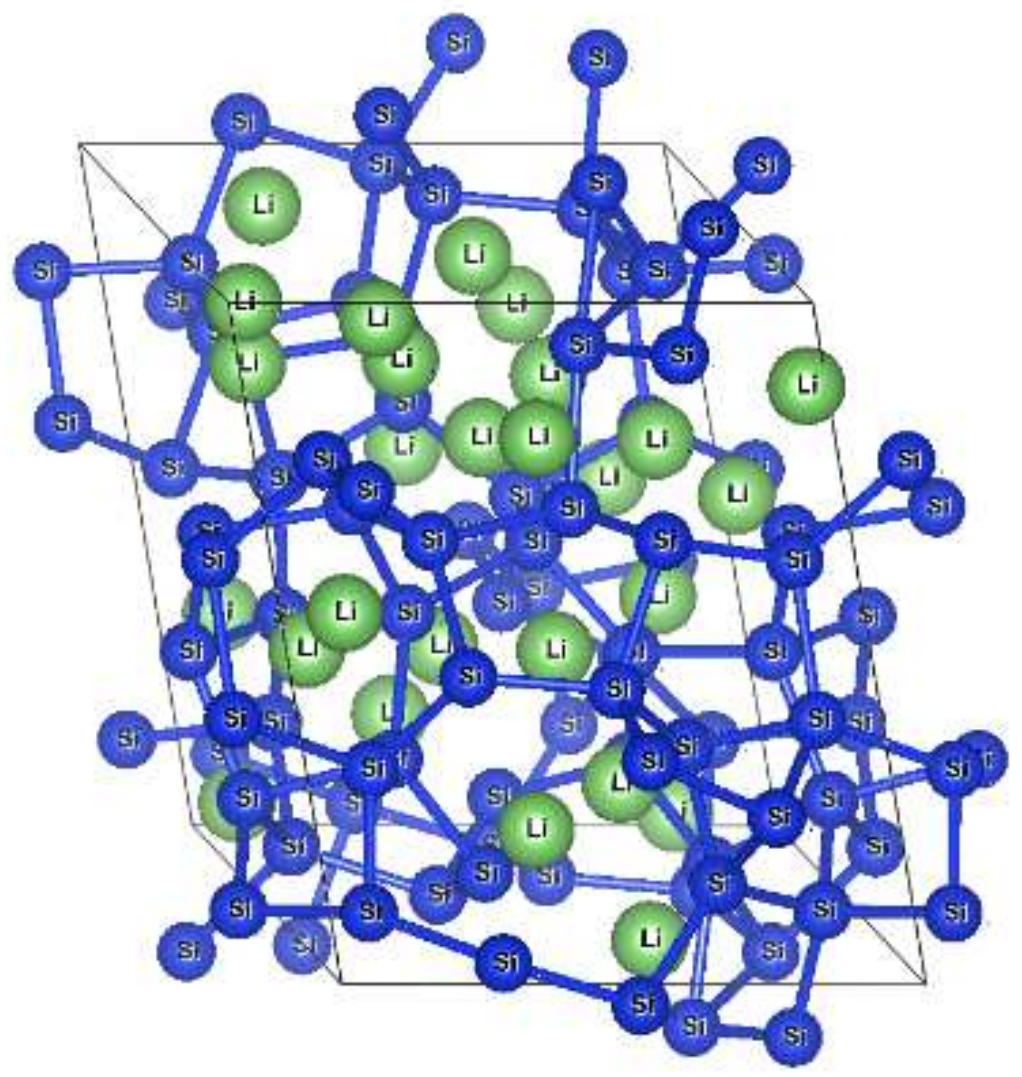




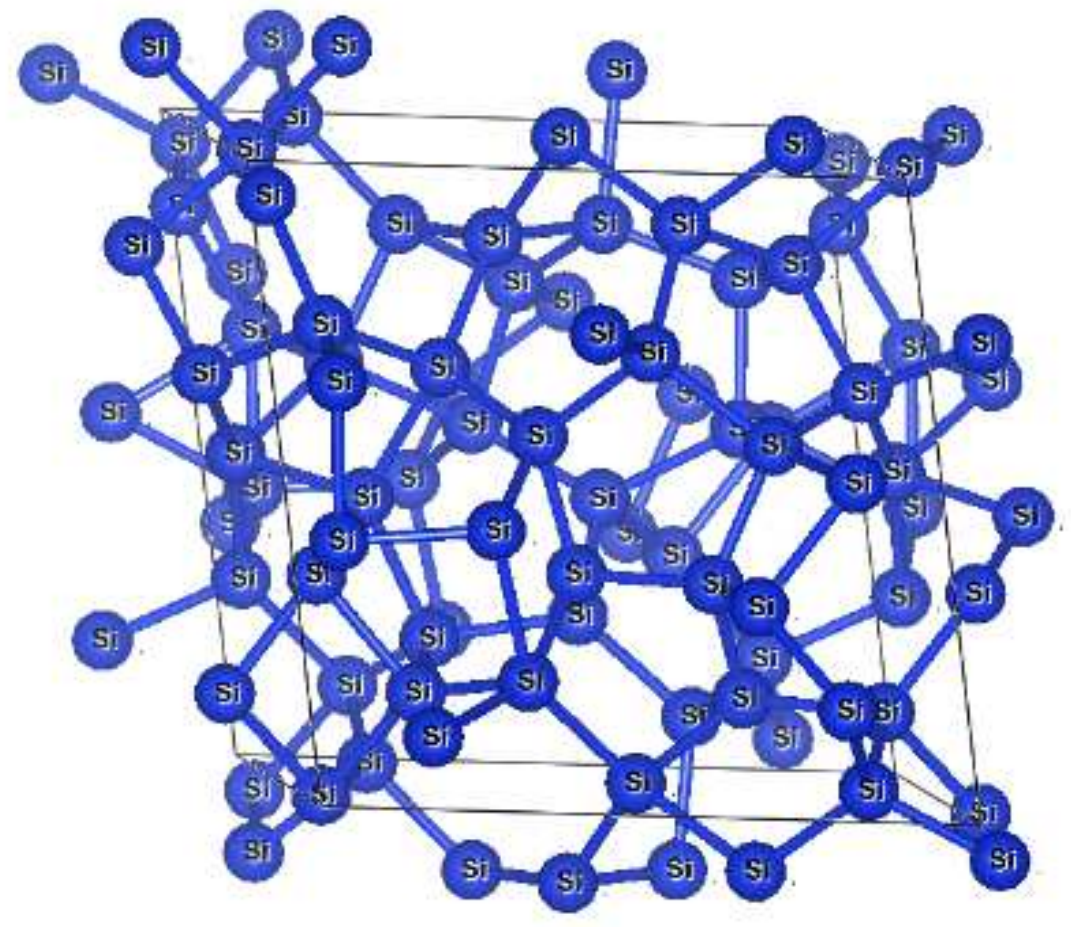

(c)

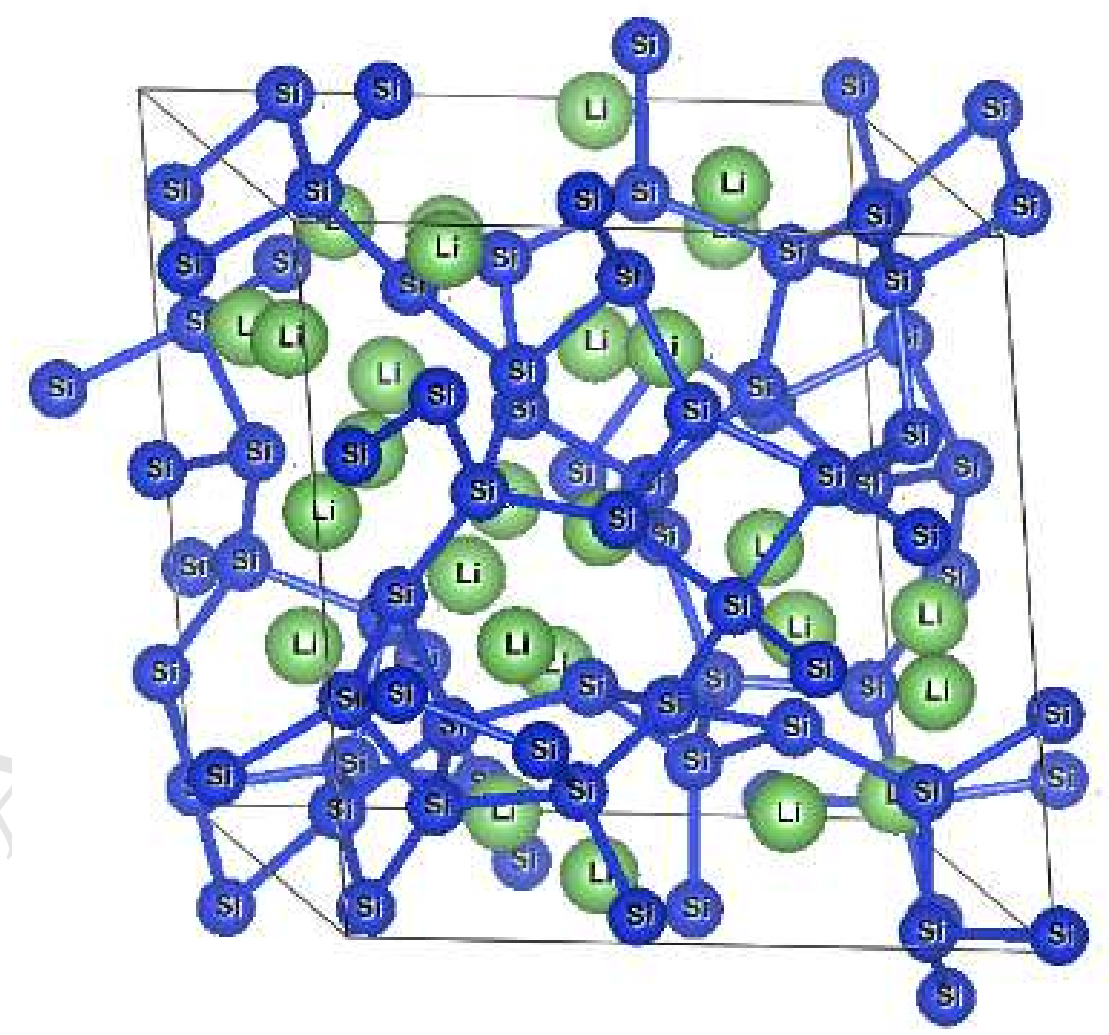

(d)

Figure1: Lithiated and pristine configuration for higher (50 atoms) and lower density (43 atoms) amorphous Si with bond connectivity. (a) and (c) show structures for high density and low density amorphous silicon configurations before lithiation. (b) and (d) show structures for high density and low density amorphous silicon configurations after lithiation. Lower connectivity and higher porosity in low density silicon 


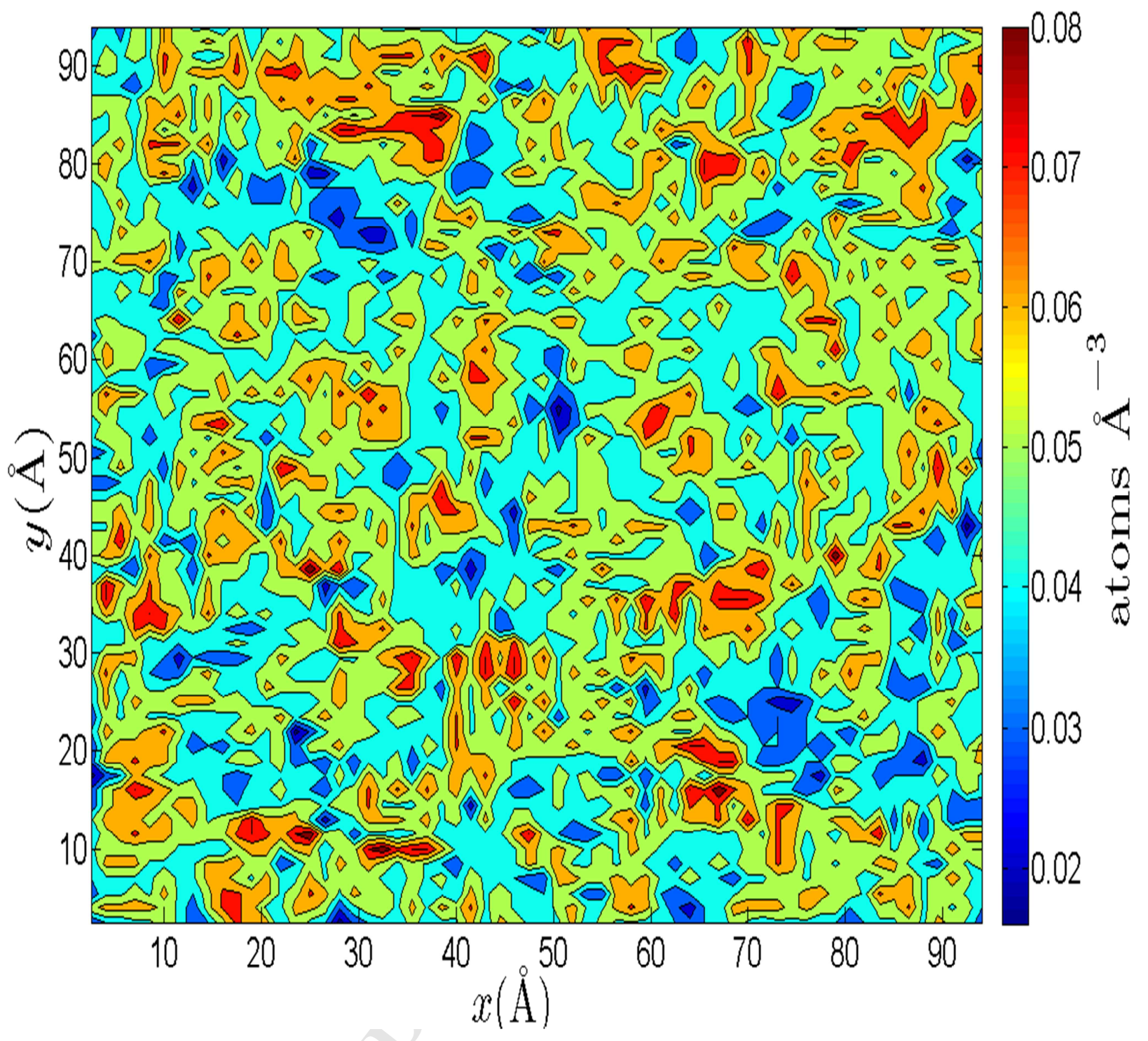

Figure 2: Contour plot of atomic density of bulk amorphous Si at $300 \mathrm{~K}$ 


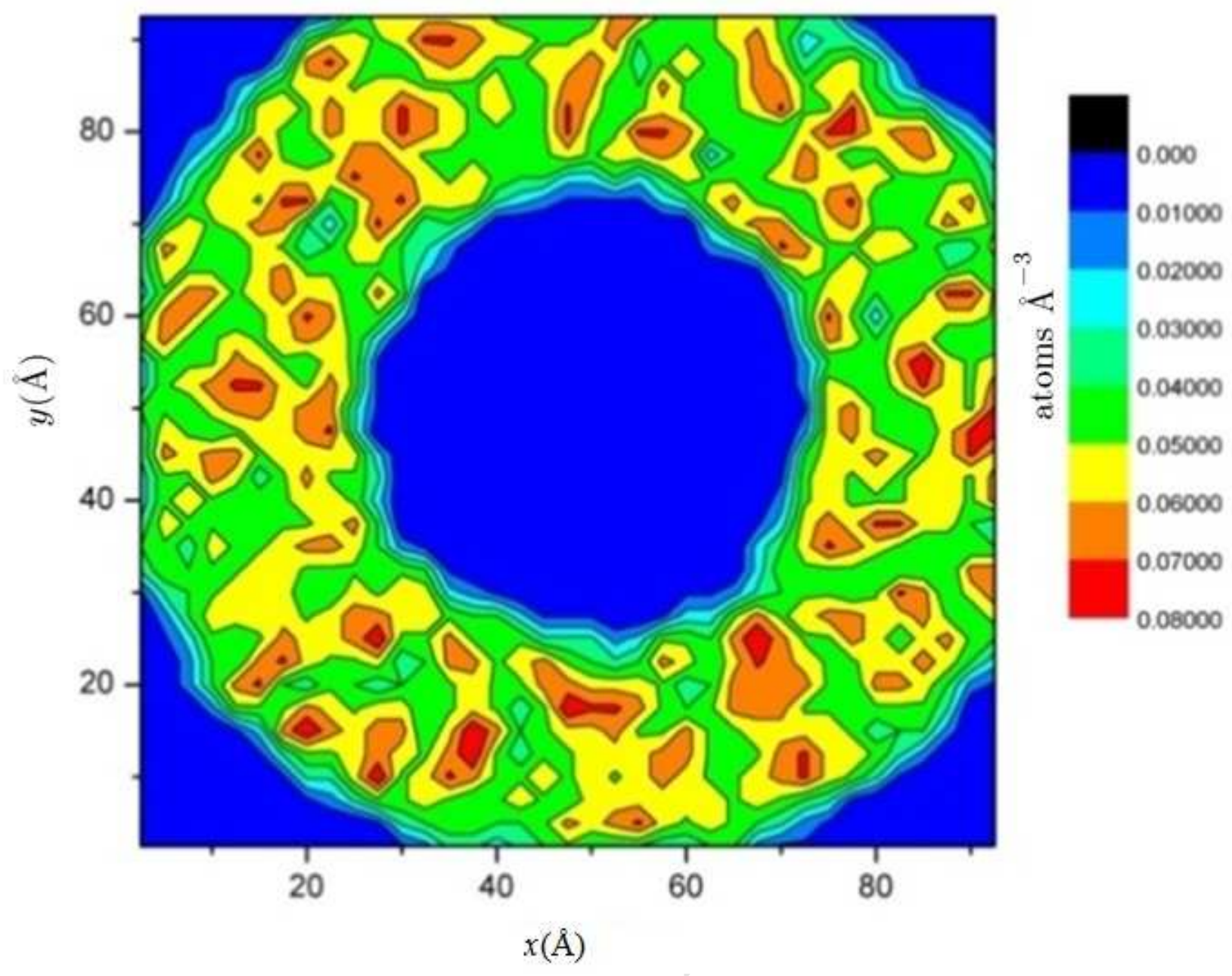

Figure 3: Contour plot of atomic density at 300K showing stability of the nano-shell 


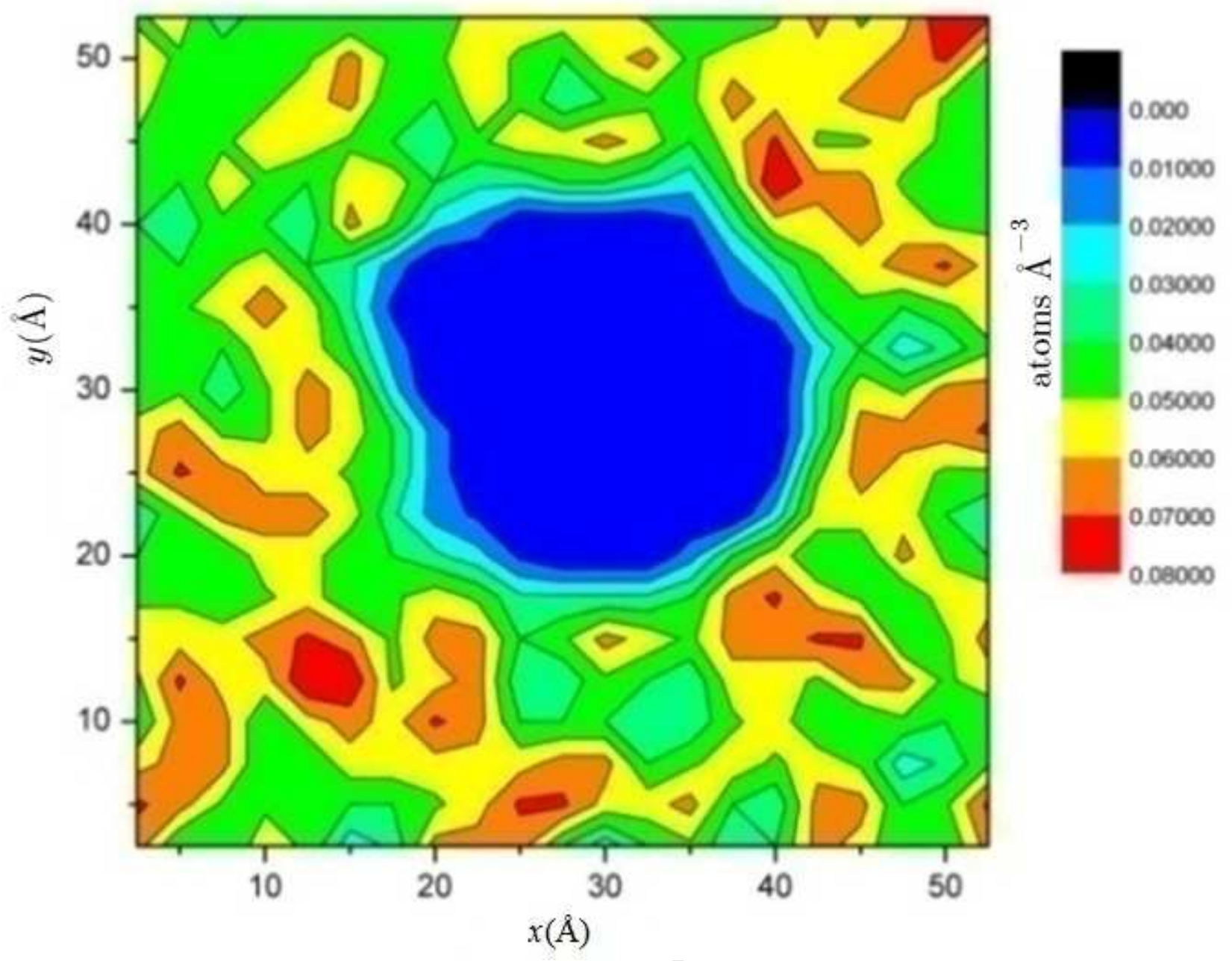

Figure 4: Contour plot of atomic density at $750 \mathrm{~K}$ showing stability of the nano-shell 


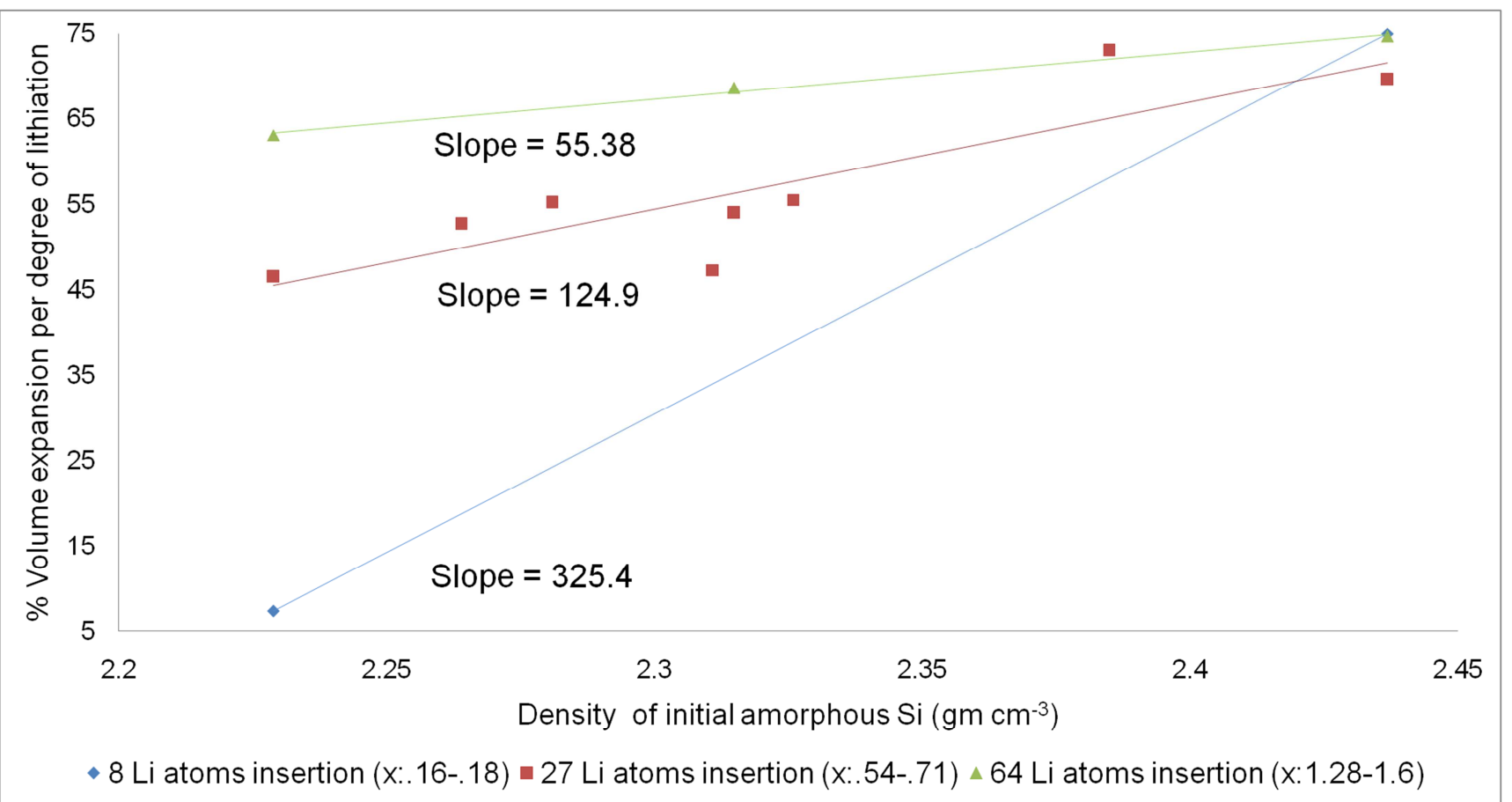

Figure 5: Variation of percentage volume expansion per degree of lithiation with density of initial amorphous Si 

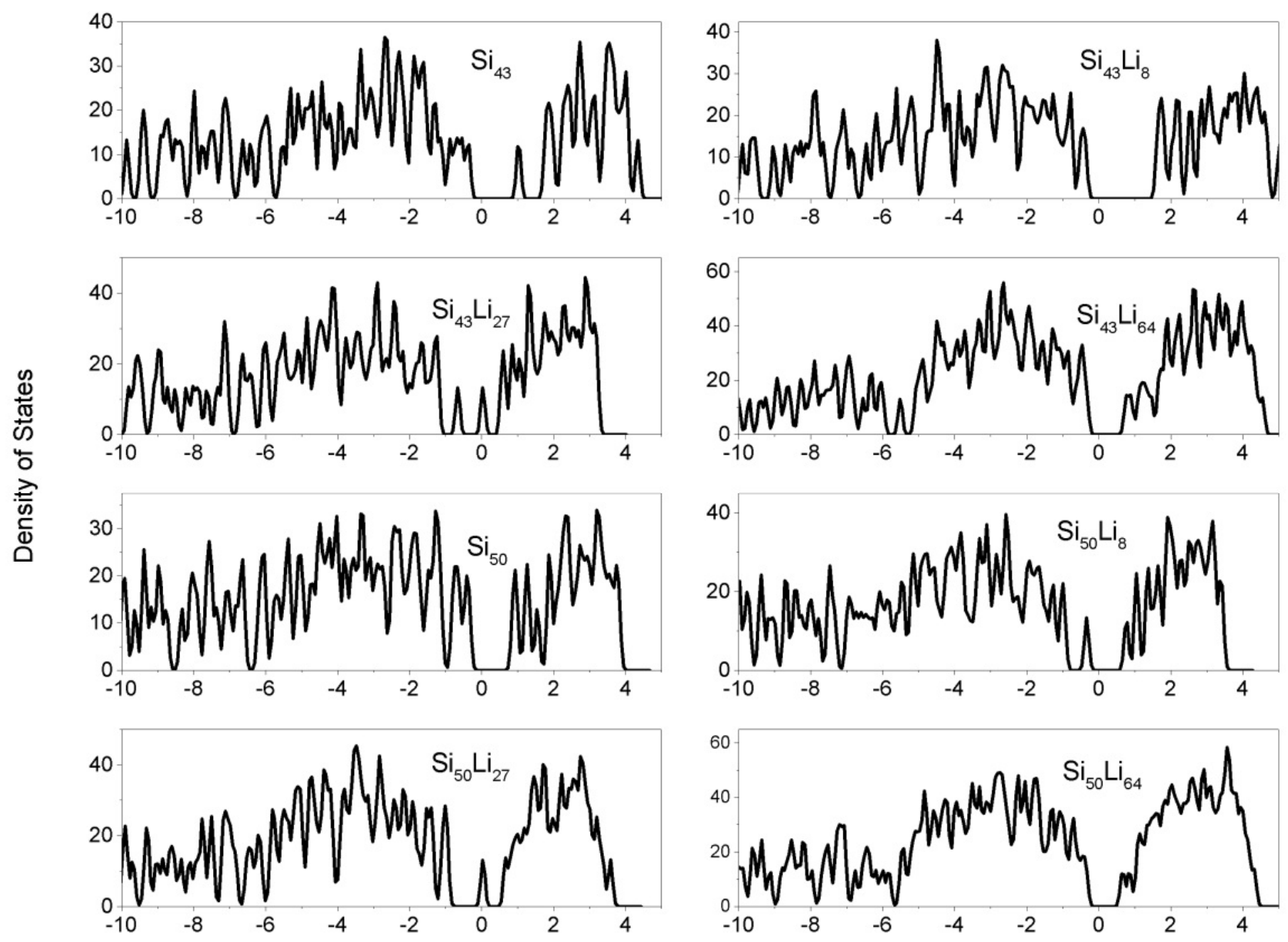

Energy (eV); Fermi energy at 0

Figure 6: Electronic DOS of amorphous Si configuration 1 and 4 (unit of energy $=\mathrm{eV}$ ) for different degrees of lithiation calculated using hybrid functional 
- Interconnected nanoshells of amorphous $\mathrm{Si}$ : best available lithium ion cell anode.

- High cycle life not understood in the light of poor $\mathrm{K}_{\mathrm{IC}}$ of amorphous $\mathrm{Si}$.

- MD reveals: atomic density of interconnected structure is $\sim 16 \%$ less than bulk $\mathrm{Si}$.

- Leads to drastic reduction (DFT) in lithiation $\sigma$ \& metal like e structure (high $\mathrm{K}_{\mathrm{IC}}$ ).

- Lowering of lithiation $\sigma$ and increase in $\mathrm{K}_{\mathrm{IC}}$ result in high cycle life. 